ARTICLE

DOI: $10.1038 / \mathrm{s} 41467-017-00677-3$

\title{
Antisite occupation induced single anionic redox chemistry and structural stabilization of layered sodium chromium sulfide
}

\author{
Zulipiya Shadike ${ }^{1,2}$, Yong-Ning Zhou ${ }^{3}$, Lan-Li Chen ${ }^{4}$, Qu Wu ${ }^{4}$,ji-Li Yue ${ }^{1}$, Nian Zhang ${ }^{5}$, Xiao-Qing Yang ${ }^{3}$, Lin Gu 6 , \\ Xiao-Song $\mathrm{Liu}^{5}$, Si-Qi Shi, ${ }^{4,7} \&$ Zheng-Wen Fu ${ }^{1}$
}

The intercalation compounds with various electrochemically active or inactive elements in the layered structure have been the subject of increasing interest due to their high capacities, good reversibility, simple structures, and ease of synthesis. However, their reversible intercalation/deintercalation redox chemistries in previous compounds involve a single cationic redox reaction or a cumulative cationic and anionic redox reaction. Here we report an anionic redox chemistry and structural stabilization of layered sodium chromium sulfide. It was discovered that the sulfur in sodium chromium sulfide is electrochemically active, undergoing oxidation/reduction rather than chromium. Significantly, sodium ions can successfully move out and into without changing its lattice parameter $c$, which is explained in terms of the occurrence of chromium/sodium vacancy antisite during desodiation and sodiation processes. Our present work not only enriches the electrochemistry of layered intercalation compounds, but also extends the scope of investigation on high-capacity electrodes.

\footnotetext{
${ }^{1}$ Shanghai Key Laboratory of Molecular Catalysts and Innovative Materials, Department of Chemistry \& Laser Chemistry Institute, Fudan University, Shanghai 200433, China. ${ }^{2}$ Chemistry Division, Brookhaven National Laboratory, Upton, NY 11973, USA. ${ }^{3}$ Department of Material Science, Fudan University, Shanghai 200433, China. ${ }^{4}$ School of Materials Science and Engineering, Shanghai University, Shanghai 200444, China. ${ }^{5}$ State Key Laboratory of Functional Materials for Informatics, Shanghai Institute of Microsystem and Information Technology, Chinese Academy of Science, Shanghai 200050, China. ${ }^{6}$ Beijing National Laboratory for Condensed Matter Physics, Institute of Physics, Chinese Academy of Sciences, Beijing 100190, China. ${ }^{7}$ Materials Genome Institute, Shanghai University, Shanghai 200444, China. Zulipiya Shadike, Yong-Ning Zhou and Lan-Li Chen contributed equally to this work. Correspondence and requests for materials should be addressed to X.-S.L. (email: xliu3@mail.sim.ac.cn) or to S.-Q.S. (email: sqshi@shu.edu.cn) or to Z.-W.F. (email: zwfu@fudan.edu.cn)
} 
ince the first commercialization in 1991, rechargeable lithium-ion battery (LIB) has powered most consumer electronic devices because of their high gravimetric and volumetric energy densities. LIB has also emerged as a key technology for electric vehicles and has been considered as a good candidate for grid-scale stationary energy storage. Over the past decade, designing and optimizing intercalation cathode materials including the layered oxides $\left(\mathrm{LiMO}_{2}, \mathrm{NaMO}_{2}\right)$, spinel oxides $\left(\mathrm{LiM}_{2} \mathrm{O}_{4}\right)$, and olivine phosphates $\mathrm{LiMPO}_{4} \quad(\mathrm{M}=$ transition metals) have contributed greatly in developing new electrode materials for high performance secondary batteries ${ }^{1-3}$. The fundamental strategy for designing intercalation cathodes used in secondary battery is on the basis of the reversible deintercalation/ intercalation of guest ions from/into the host framework without changing the skeleton structure. In general, most of layered intercalation compounds for secondary batteries involve the cationic reversible redox processes ${ }^{4-7}$. These compounds, like $\mathrm{LiCoO}_{2}{ }^{4}, \mathrm{NaCrO}_{2}{ }^{5}, \mathrm{LiNi}_{1 / 3} \mathrm{Mn}_{1 / 3} \mathrm{Co}_{1 / 3} \mathrm{O}_{2}{ }^{6}$, and $\mathrm{LiMS}_{2}{ }^{7}(\mathrm{M}=\mathrm{Ti}$, $\mathrm{V}, \mathrm{Cr}$ ), can be described as an alternate layer structure with alkali cation sheets sandwiched between transition-metal oxide/sulfide slabs. The transition metal ions as the redox centers could be reduced to a lower oxidation state by electrochemical intercalation of guest ions. Recently, the contributions from anionic redox reactions are reported in high-capacity layered oxides and gaining increasing attentions ${ }^{8-12}$. Some Li-rich cathode materials, such as $\mathrm{Li}_{1.20} \mathrm{Mn}_{0.54} \mathrm{Co}_{0.13} \mathrm{Ni}_{0.13} \mathrm{O}_{2}{ }^{8}, \mathrm{Li}_{2} \mathrm{Ru}_{1-y} \mathrm{Sn}_{y} \mathrm{O}_{3}(0<y<1)^{9}$, $\mathrm{Li}_{2} \mathrm{Ru}_{1-y} \mathrm{Ti}_{y} \mathrm{O}_{3} \quad(0 \leq y \leq 1)^{10}, \quad \mathrm{Li}_{4} \mathrm{FeSbO}_{6}{ }^{11}$, and $\mathrm{Li}_{2} \mathrm{Ir}_{1-x} \mathrm{Sn}_{x} \mathrm{O}_{3}$ $(0<x<1)^{12}$, exhibit a cumulative cationic and anionic $\left(\mathrm{O}^{2-} / \mathrm{O}_{2}{ }^{2-}\right)$ reversible redox chemistry when Li ions reversibly deintercalate/intercalate from/into these compounds. From both experimental ${ }^{8}$ and theoretical ${ }^{13}$ points of view, recent studies revealed that the anionic redox was triggered by forming

a

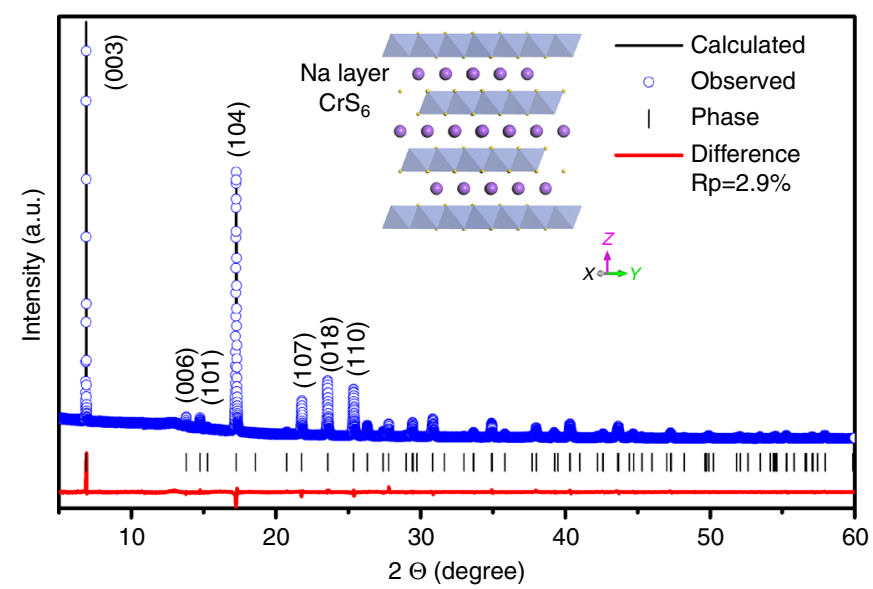

b
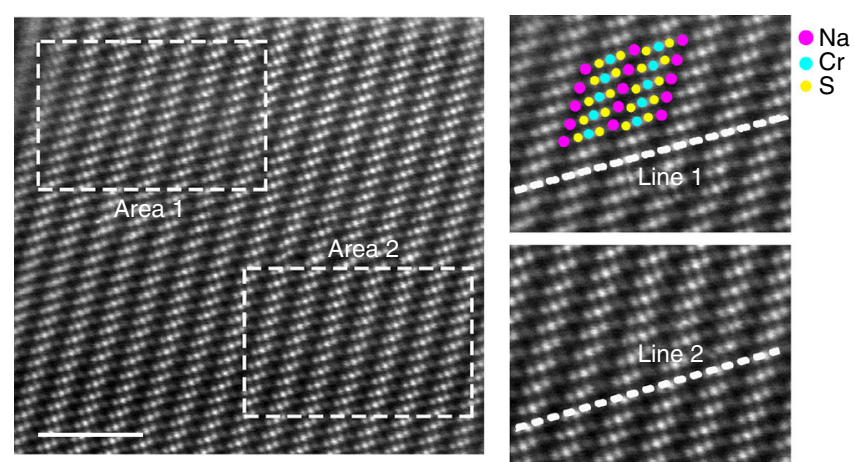

C

$x$ in $\mathrm{Na}_{1-x} \mathrm{CrS}_{2}$

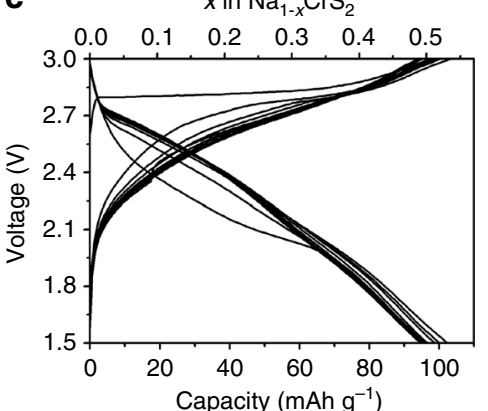

d

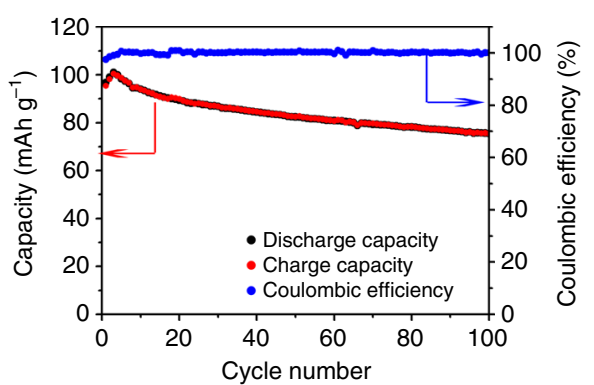

Fig. 1 Structural, morphological, and electrochemical performance of $\mathrm{NaCrS}_{2}$. a XRD patterns of powder $\mathrm{NaCrS}$ (blue circle), calculated profile (black solid line), and their difference (red solid line). Bragg positions are indicated as black vertical tick marks. In the inset for the structure schematic of $\mathrm{NaCrS}_{2}$, legend: purple $(\mathrm{Na})$, blue $(\mathrm{Cr})$, and yellow balls (S); b HAADF-STEM image of the pristine $\mathrm{NaCrS}_{2}$ particle, scale bar 2 nm; c Galvanostatic charge/discharge curves, d cyclic performances and Coulombic efficiencies of $\mathrm{NaCrS}_{2}$ electrode at $0.5 \mathrm{C}$ 
a

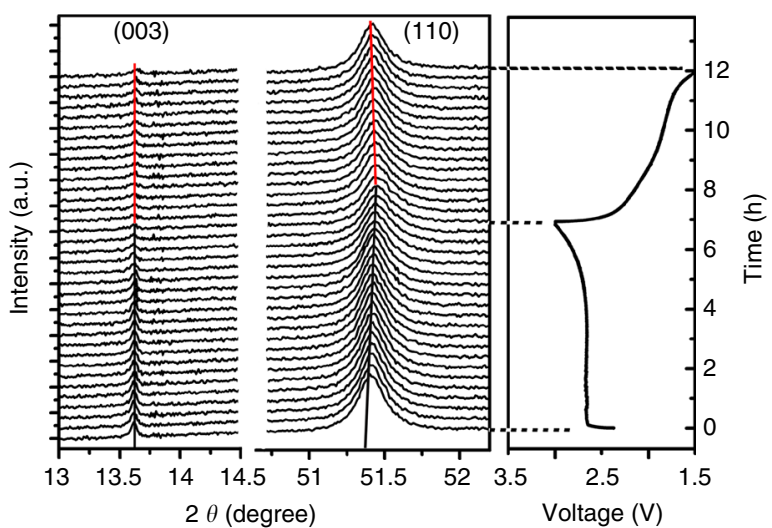

b

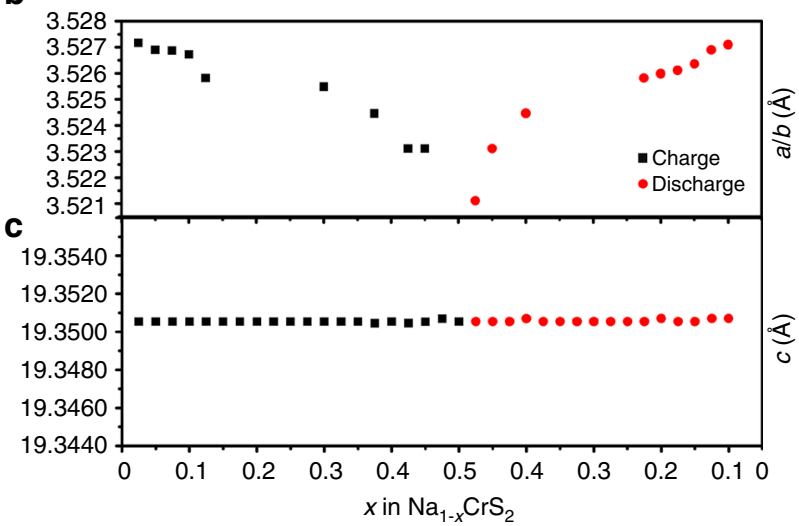

Fig. 2 Structural evolution of $\mathrm{NaCrS}_{2}$ during sodium deintercalation and intercalation. a In situ XRD during the initial cycle for $\mathrm{NaCrS}_{2}$, corresponding voltage curve is shown on the right. The $2 \theta$ is converted to the corresponding angle for $\lambda=1.54 \AA(\mathrm{Cu}-\mathrm{K} \alpha)$ from the real wavelength $\lambda$ $=0.7747 \AA$ used for synchrotron XRD experiments. Evolution of lattice parameters $\mathbf{b} a / b$ and $\mathbf{c} c$ calculated from the in situ XRD during the first charge/discharge process

non-bonding oxygen states, which was created due to that those $\mathrm{O} 2 p$ orbitals in Li-O-Li configuration have no transition metal orbitals with which it can hybridize. The oxidation of oxygen takes place on the orphaned electrons in Li-O-Li configuration. The increased capacity arises from the fact that two redox bands can be accessed by $\mathrm{MO}^{*}$ states and non-bonding oxygen states in Li-rich layer-structured and cation-disordered cathode materials ${ }^{14}$. Although this so-called "anion-cation redox competition" behavior was first discussed by Rouxel in $1996^{15}$ with some lesselectronegative chalcogenides, the current strategies for designing new high-capacity intercalation-type electrodes are mainly limited to the optimized transition metal redox properties and the utilization of the redox of oxygen. Recently, Du and Goodenough et al. ${ }^{16}$ investigated the sole anionic redox in a P3-layered $\mathrm{Na}_{0.6}\left(\mathrm{Li}_{0.2} \mathrm{Mn}_{0.8}\right) \mathrm{O}_{2}$, and found that the holes in $\mathrm{O}-2 p$ bands were introduced during desodiation, but cannot cycle reversibly. Here, a sole reversible anionic redox chemistry of $\mathrm{S}^{2-} / \mathrm{S}_{2}{ }^{2-}$ is triggered by the $\mathrm{Cr} / \mathrm{V}^{\prime}{ }_{\mathrm{Na}}$ ( $\mathrm{Na}$ vacancy: $\mathrm{V}_{\mathrm{Na}}^{\prime}$ in Kröger-Vink notation) antisite, without the redox of transition metal. The relationship between the redox chemistry of $\mathrm{S}^{2-} / \mathrm{S}_{2}{ }^{2-}$ and its electronic structure is systematically investigated with multi-probe experimental characterizations and theoretical calculations. The motivation of this work is to enrich the reversible redox chemistry of layer-structured intercalation compounds for understanding the nature of their structural and electronic property variations during the deintercalation/intercalation of guest ions.
In this work, the deintercalation/intercalation reaction of $\mathrm{NaCrS}_{2}$ as a model-layered compound with the typical $\mathrm{S}^{2-} / \mathrm{S}_{2}{ }^{2-}$ redox is presented. Typical reversible redox chemistry of sulfur, an "abnormal" unit cell breathing behavior and $\mathrm{Cr} / \mathrm{V}^{\prime}{ }_{\mathrm{Na}}$ antisite are observed during the first desodiation/sodiation processes. Density functional theory (DFT) calculations reveal that the top of valance band of $\mathrm{NaCrS}_{2}$ is mainly populated by $\mathrm{S}$ electrons. Therefore, sulfur undergoes redox chemistry for charge compensation during sodium removal. Besides, the occurrence of $\mathrm{Cr} / \mathrm{V}^{\prime}{ }_{\mathrm{Na}}$ antisite triggers the redox of sulfur and is found to be responsible for the "abnormal" unit cell breathing without changing its lattice parameter $c$.

\section{Results}

Structural, morphological, and electrochemical performance. The crystal structure of $\mathrm{NaCrS}_{2}$ is measured by synchrotron $\mathrm{X}$-ray diffraction (XRD). The refined pattern is presented in Fig. 1a. All Bragg reflections are indexed by using a rhombohedral symmetry with space group $R-3 m$ (No. 166). This is a typical O3-type layered structure $(a=b=3.5270(4) \AA, c=19.3506(1) \AA)$ and no crystalline impurities are observed. The crystal structure schematic is illustrated in inset of Fig. 1a. The Rietveld refinement shows reasonable small $\mathrm{R}$ factors $\left(R_{\mathrm{p}}=2.9 \%, R_{\mathrm{wp}}=3.9 \%\right)$ and high goodness of fit (GOF $\left.\left(\chi^{2}\right)=4.67\right)$. The structure parameters are listed in Supplementary Table 1. The high intensity ratio (1.55) of (003)/(104) and clearly separated (110) and (018) peaks imply a clear layered $\mathrm{O} 3$ structural configuration without $\mathrm{Cr} / \mathrm{Na}$ antisite defects between the oxygen layers ${ }^{17-19}$. It is also confirmed by TEM observations at atomic-scale resolution on the pristine $\mathrm{NaCrS}_{2}$ (Fig. $1 \mathrm{~b}$ and Supplementary Figs. 1 and 2). Figure $1 \mathrm{~b}$ exhibits the typical image of high-angle-annular-darkfield (HAADF) for $\mathrm{NaCrS}_{2}$ sample at atomic-level projected along [100] direction. Line scans are performed on the surface (line 1) and bulk (line 2) of a particle. The corresponding contrast curves from the line scans are presented in Supplementary Fig. 1a, b. The peaks in the curves correspond to $\mathrm{Cr}, \mathrm{S}$, and $\mathrm{Na}$ atomic columns in the HAADF image. The intensity ratio between $\mathrm{Na}$ and $\mathrm{Cr}$ column is $\sim 14.59 \%$. From STEM images and contrast curves of line scans, it can be concluded that the structural distribution is homogeneous from surface to bulk of the $\mathrm{NaCrS}_{2}$ particles. $\mathrm{NaCrS}_{2}$ particles are in irregular shape with a size range of 2-4 $\mu \mathrm{m}$ (Supplementary Fig. 3).

Figure 1c shows the charge and discharge curves of $\mathrm{NaCrS}_{2}$ at $0.5 \mathrm{C}$. During the initial charge, $\mathrm{NaCrS}_{2}$ electrode displays a flat voltage at $2.85 \mathrm{~V}$ and delivers a high capacity of $95 \mathrm{mAh} \mathrm{g}^{-1}$ $\left(0.49 \mathrm{Na}^{+}\right.$per $\left.\mathrm{NaCrS}_{2}\right)$, which is smaller than that of $\mathrm{Na}_{x} \mathrm{VS}_{2}$ and $\mathrm{Na}_{x} \mathrm{TiS}_{2}$ electrodes ${ }^{20}\left(160 \mathrm{mAh} \mathrm{g}^{-1}\right)$. The initial discharge profile includes a slopy region from 2.8 to $2.1 \mathrm{~V}$ and a flat plateau at $2.0 \mathrm{~V}$. The first discharge capacity $92 \mathrm{mAh} \mathrm{g}^{-1}$ is presented. In subsequent three cycles, the charge and discharge capacities gradually increase due to the activation process of electrode, e.g., the specific charge and discharge capacity of 104.1 and $103.4 \mathrm{mAh} \mathrm{g}^{-1}$ is obtained, respectively, in the third cycle. The coulombic efficiency is $99.3 \%$. The cyclic performance and coulombic efficiency of $\mathrm{NaCrS}_{2}$ electrode are presented in Fig. 1d. The capacity keeps decreasing after the 50 cycles. A capacity of $78.5 \mathrm{mAh} \mathrm{g}^{-1}$ can still be obtained after 100 cycles, whereas the coulombic efficiency increases during the initial 10 cycles and then reaches almost $100 \%$ after 100 cycles. At $0.1 \mathrm{C}$ shown in Supplementary Fig. 4, the initial charge capacity is $93.2 \mathrm{mAh} \mathrm{g}^{-1}$. The reversible capacity also increases in a few cycles at the beginning and gets to the maximum value $107.3 \mathrm{~mA} \mathrm{~h} \mathrm{~g}^{-1}$, then decreases to $78.6 \mathrm{mAh} \mathrm{g}^{-1}$ at the 100th cycle. The first five cyclic voltammograms of $\mathrm{NaCrS}_{2}$ electrode are presented in Supplementary Fig. 5. It shows that the cathodic/anodic 
a
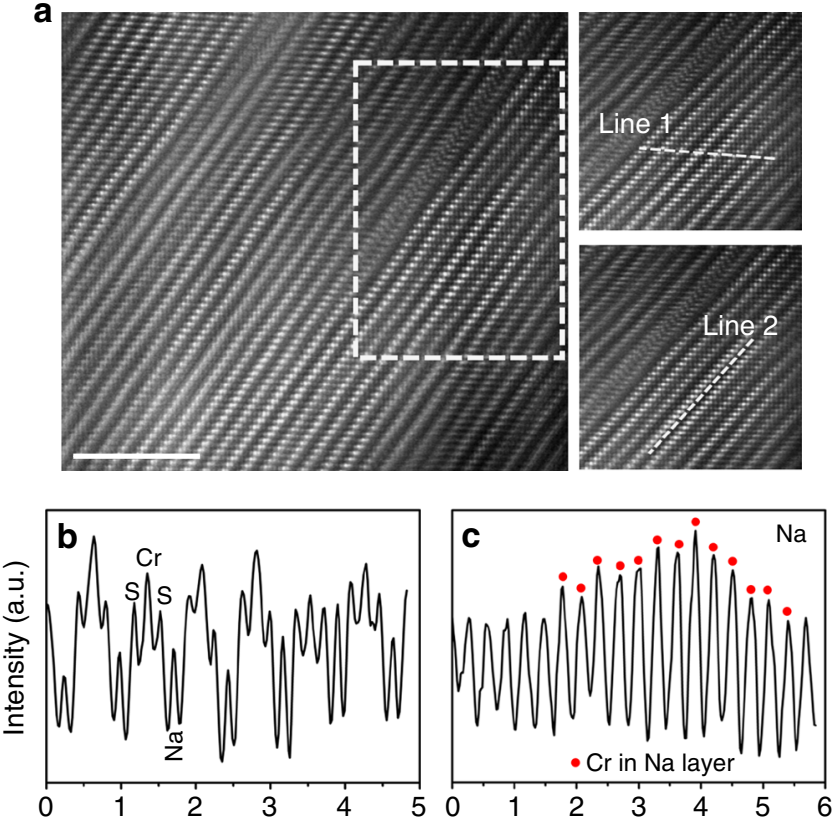

Distance (nm)

Fig. 3 Atomic structure of $\mathrm{NaCrS}_{2}$ after charge. a HAADF-STEM image of the desodiated particle $\left(\mathrm{Na}_{1-x} \mathrm{CrS}_{2}: x=0.5\right.$ calculated from capacity), scale bar $5 \mathrm{~nm}$. b, c The contrast profiles of the regions scanned by line 1 ( $\mathrm{Cr}, \mathrm{S}$, and $\mathrm{Na}$ ions columns) and 2 ( $\mathrm{Na}$ columns), respectively. (Red circle represents $\mathrm{Cr}$ ion in the $\mathrm{Na}$ layer)

peaks emerge at $2.85 / 2.05 \mathrm{~V}$ in the first cycle, which are close to the galvanostatic charge/discharge voltage plateaus in the first cycle in Fig. 1c.

Na-driven structural evolution during cycling. To monitor the structural changes of $\mathrm{NaCrS}_{2}$ electrode upon sodium deintercalation/intercalation, synchrotron-based in situ XRD is carried out. Figure 2a shows a series of XRD patterns obtained in the initial cycle. In this work, the fully charged state of the $\mathrm{Na}_{1-x} \mathrm{CrS}_{2}$ electrode is defined by the samples charged to $3.0 \mathrm{~V}\left(\mathrm{Na}_{0.5} \mathrm{CrS}_{2}\right)$. According to the crystallography theory, (003) and (110) peaks reflect changes along $c$ and $a$ axes of the layered structure, respectively. During the charge process, the (110) peak gradually moves toward higher $2 \theta$ angles when $x$ value is increased from 0.0 to 0.5 in $\mathrm{Na}_{1-x} \mathrm{CrS}_{2}$, indicating a solid solution reaction with the continuous lattice contraction along the $a$ axis. During the discharge process, the (110) peak reversibly moves back to its original position when $x$ value decreases from 0.5 to 0 in $\mathrm{Na}_{1-x} \mathrm{CrS}_{2}$. Very interestingly, the $2 \theta$ angle of (003) diffraction peak keeps unchanged in the entire charge/discharge processes, implying that the lattice parameter $c$ remains almost constant. The lattice parameter evolution of $\mathrm{NaCrS}_{2}$ electrode during the initial cycle is shown in Fig. $2 \mathrm{~b}$, c. From $x=0$ to 0.5 during charge process, the lattice parameter $a$ decreases from 3.527 to $3.521 \AA$ and then reversibly increases back to $3.527 \AA$ during the discharge process. On the contrary, the lattice parameter $c$ keeps unchanged, resulting in a very small unit cell volume change during desodiated/sodiated process. The structure evolution and lattice parameter change of $\mathrm{NaCrS}_{2}$ electrode during the third cycle are found to be almost consistent with those during the first cycle (Supplementary Fig. 6). No other peak is observed, indicating that no new structure is formed in the subsequent cycles. The invariableness of lattice parameter $c$ of $\mathrm{NaCrS}_{2}$ electrode during charge/discharge process is quite unusual compared with many other layered cathode materials, in which the parameter $c$ is mostly increasing during charge and decreasing during discharge known as "normal" unit cell breathing behavior ${ }^{2 \mathrm{~T}}$. To our knowledge, the unchanged parameter $c$ was only observed in layered $\mathrm{LiNbO}_{2}$ system ${ }^{22}$. In the layered cathodes with "normal" unit cell breathing behavior, the increasing lattice parameter $c$ is due to the expansion of the interlayer spacing caused by the enhanced repulsion force between the two neighboring oxygen layers in delithiation (or desodiation). However, in the $\mathrm{LiNbO}_{2}$ system, the expansion of the interlayer spacing is compensated by the contraction of the $\mathrm{NbO}_{6}$ trigonal prism along the $c$ axis because of the deformation of $\mathrm{NbO}_{6}$ trigonal prism during charge. Because the layered structure of $\mathrm{NaCrS}_{2}$ with edgesharing of $\mathrm{CrO}_{6}$ octahedra is different from that of $\mathrm{LiNbO}_{2}$ with edge-sharing $\mathrm{NbO}_{6}$ trigonal prisms, the mechanism of unchanged parameter $c$ in layered $\mathrm{LiNbO}_{2}$ could not be applied for $\mathrm{NaCrS}_{2}$.

In order to understand the "abnormal" unit cell breathing mechanism of $\mathrm{NaCrS}_{2}$ electrode during the first charge process, the structure of the first charged sample at atomic scale is investigated by STEM. As shown in Fig. 3a, the contrast of $\mathrm{Na}, \mathrm{Cr}$, and $\mathrm{S}$ atomic columns changes a lot, compared with the pristine sample. The line profiles of Fig. 3b, c are associated with the dash line 1 and 2, respectively. The intensity ratio between $\mathrm{Na}$ and $\mathrm{Cr}$ column is $\sim 49.81 \%$, which is higher than the ratio in pristine $\mathrm{NaCrS}_{2}$ sample, implying the existence of cation mismatch. Besides, the intensity fluctuation of $\mathrm{Na}$ column confirms the uneven Cr occupation in $\mathrm{Na}_{0.5} \mathrm{CrS}_{2}$ (red cycle represents $\mathrm{Cr}$ ion in the Na layer). Similar phenomena have been observed in $\mathrm{LiCrO}_{2}$ and $\mathrm{LiVO}_{2}$ electrodes ${ }^{23}{ }^{24}$. Such $\mathrm{Cr}$ migration into $\mathrm{Na}$ sites may be responsible for the unchanged lattice parameter $c$.

Detection of Cr valance state. Ex situ Cr K-edge XAS experiments are carried out to examine valance states of $\mathrm{Cr}$ during charge and discharge. The red blocks on the curves in Fig. 4a mark the positions for XAS spectrum collection. The X-ray absorption near-edge structure (XANES) spectra of Cr K-edge at various charge/discharge states are presented in Fig. $4 \mathrm{~b}$. No obvious change of the spectra is observed during the initial cycle, indicating that very limited redox reaction for $\mathrm{Cr}$ ions takes place during the entire electrochemical cycle. This phenomenon is quite different from the other layer-structured cathodes ${ }^{25}$. The Fourier transformed extended X-ray absorption fine structure (FT-EXAFS) spectra of the pristine and fully charged electrodes are shown in Fig. 4c, d. The first peak at $\sim 2.0 \AA$ is attributed to the single scattering path from the closest $\mathrm{S}$ ions to the core $\mathrm{Cr}$ ions, and the peak at $\sim 3.25 \AA$ is due to the scattering from the nearest $\mathrm{Cr}$ ions in $\mathrm{Cr}$ layer. The $R$ values of these peaks are about 0.3-0.4 Å shorter than the real bond lengths, because they are not phase corrected ${ }^{25}$. Supplementary Table 2 lists the structure parameters derived from fitting. It is observed that the atomic distances of both $\mathrm{Cr}-\mathrm{S}$ and $\mathrm{Cr}-\mathrm{Cr}$ are decreasing upon charge, implying the shrinking of $\mathrm{Cr}-\mathrm{S}_{6}$ octahedrons and $\mathrm{Cr}^{-} \mathrm{Cr}_{6}$ hexagons. These are consistent with XRD results showing that the lattice parameter $a$ decreases during the charge process.

EPR spectra. EPR spectroscopy is employed to further monitor the sodium content-induced changes in the oxidation states of $\mathrm{Cr}$ or $\mathrm{S}$ ions in $\mathrm{Na}_{x} \mathrm{CrS}_{2}$ series, and Fig. $4 \mathrm{f}$ shows the EPR spectra of $\mathrm{Na}_{x} \mathrm{CrS}_{2}$ series at room temperature (RT). The $\mathrm{Cr}^{3+}$ ion in $\mathrm{NaCrS}_{2}$ has the $3 d^{3}$ electron configuration, which is EPR-active owing to existence of unpaired electrons, while $\mathrm{S}_{2}{ }^{4-}$ in $\mathrm{NaCrS}_{2}$ is EPR-inactive, because all electrons are paired ${ }^{26}$. All spectra consist of single Lorentzian line, and $g$ factor is calculated using 

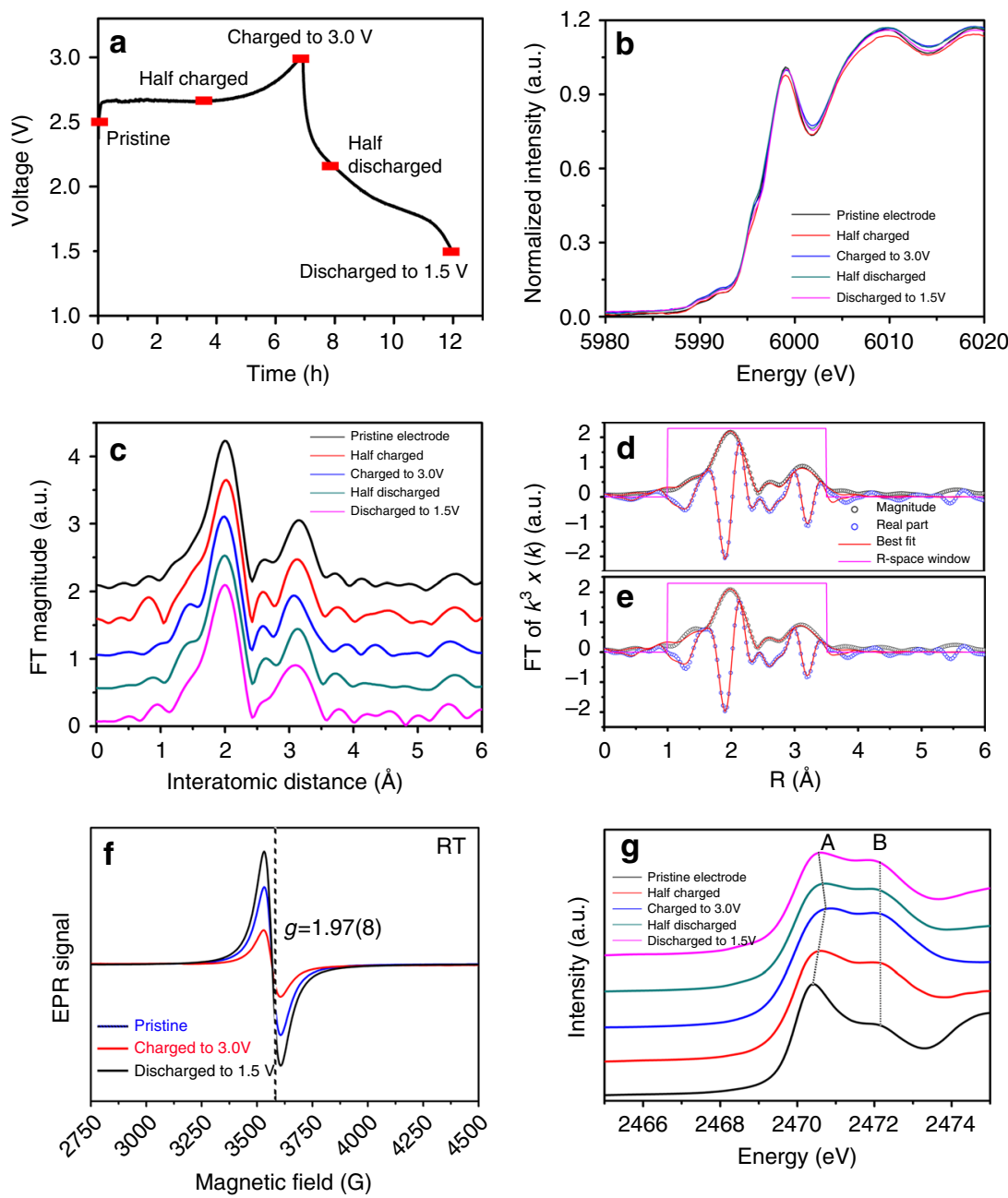

Fig. 4 Detection of $\mathrm{Cr}$ and $\mathrm{S}$ valance state during various charge-discharge stages. a Charge and discharge curves of $\mathrm{NaCrS}_{2}$ electrode for ex situ XAS. b $\mathrm{Cr}$ K-edge XANES spectra of $\mathrm{NaCrS}_{2}$ electrodes at various states. c Corresponding FT-EXAFS spectra of the $\mathrm{NaCrS}_{2}$ electrode at various charge and discharge stages. Calculated (solid red line) and experimental (solid and open circle) FT-EXAFS spectra for $\mathbf{d}$ pristine and $\mathbf{e}$ fully charged samples. $\mathbf{f}$ EPR spectra of pristine $\mathrm{NaCrS}_{2}$, fully charged and discharged samples recorded at room temperature. $\mathbf{g} \mathrm{S}$ K-edge XANES spectra of $\mathrm{NaCrS} 2$ at the initial cycle

the following relationship ${ }^{27}$ :

$$
h v_{\mathrm{r}}=g \mu_{\mathrm{B}} H_{\mathrm{r}} .
$$

The effective $g$ value of $1.97(8)$ in the magnetic field of $3570 \mathrm{G}$ obtained from RT is associated with contributions from both exchange-coupled pairs of $\mathrm{Cr}^{3+28,29}$. It is undoubted that the $\mathrm{Cr}^{3+}$ EPR-signal and $g$ factor are almost unchanged during charge/discharge processes, indicating the valence state of $\mathrm{Cr}$ ions remains unchanged during the first cycle. In addition, no S-signal is detected in the charged sample, which can be explained by the formation of $\left(\mathrm{S}_{2}\right)^{2-}$ species that have no unpaired electron as shown in Supplementary Fig. 8, thus are EPR-inactive.

S K-edge XANES. To examine valence states of $\mathrm{S}$ for $\mathrm{NaCrS}_{2}$ during cycling, ex situ $S$ K-edge XANES spectra are measured. As presented in Fig. 4g, two peaks at around 2470.3 and $2472.1 \mathrm{eV}$ in S K-edge XANES spectra of the pristine $\mathrm{NaCrS}_{2}$ are observed, corresponding to these unoccupied $t_{2 g}$ and $e_{g}$ bands, respectively $^{30}$. These bands are derived from the hybridization of sulfur $3 p$ states and delocalized $\mathrm{Cr} 3 d$ states. The peak distance (band splitting of $t_{2 g}-e_{g}$ ) about $1.8 \mathrm{eV}$ is close to that of $\mathrm{LiTiS}_{2}{ }^{31}$. In the charge process, the shapes of $S \mathrm{~K}$-edge XANES spectra change obviously. A gradually positive shift of the edge peak A to high energy is clearly observed, and there is a large displacement of about $0.4 \mathrm{eV}$ between the pristine and fully charged states. More interestingly, the intensities of peak $B$ gradually increase during charge. Previous studies reported that a significant increase of the edge peak intensity in S K-edge XANES spectra for lithium deintercalation in $\mathrm{Li}_{x} \mathrm{TiS}_{2}(0 \leq x \leq 1)$ is indicative of the electron transfer involving in sulfur ${ }^{31}, 32$. The position shifts of peak A and the intensity increments of peak B during charge should mainly result from the contributions of the formation of new chemical bonds to the sulfur atoms. This new peak might emerge around $2742.1 \mathrm{eV}$ and its intensity increases during the charge process. Therefore, such a new peak indicates the oxidation of $\mathrm{S}^{2-}$ during the sodium deintercalation process. These variations in S K-edge XANES spectra show reversibility during discharge process, which strongly confirm that the spectral evolution is related to the electrochemical sodium intercalation/ deintercalation reactions. From the results above, it can be deduced that charge compensation of $\mathrm{NaCrS}_{2}$ during charge and discharge is mainly achieved by the redox of $\mathrm{S}^{2-}$.

S 2p XPS spectra. To further confirm the electron structure of S during charge and discharge, XPS measurements are carried out on $\mathrm{NaCrS}_{2}$ at pristine (Fig. 5a), fully charged (Fig. 5b), and fully discharged states (Fig. $5 \mathrm{c}$ ). For the pristine sample, the $\mathrm{S} 2 p$ spectra can be deconvoluted into three peaks: two peaks at 

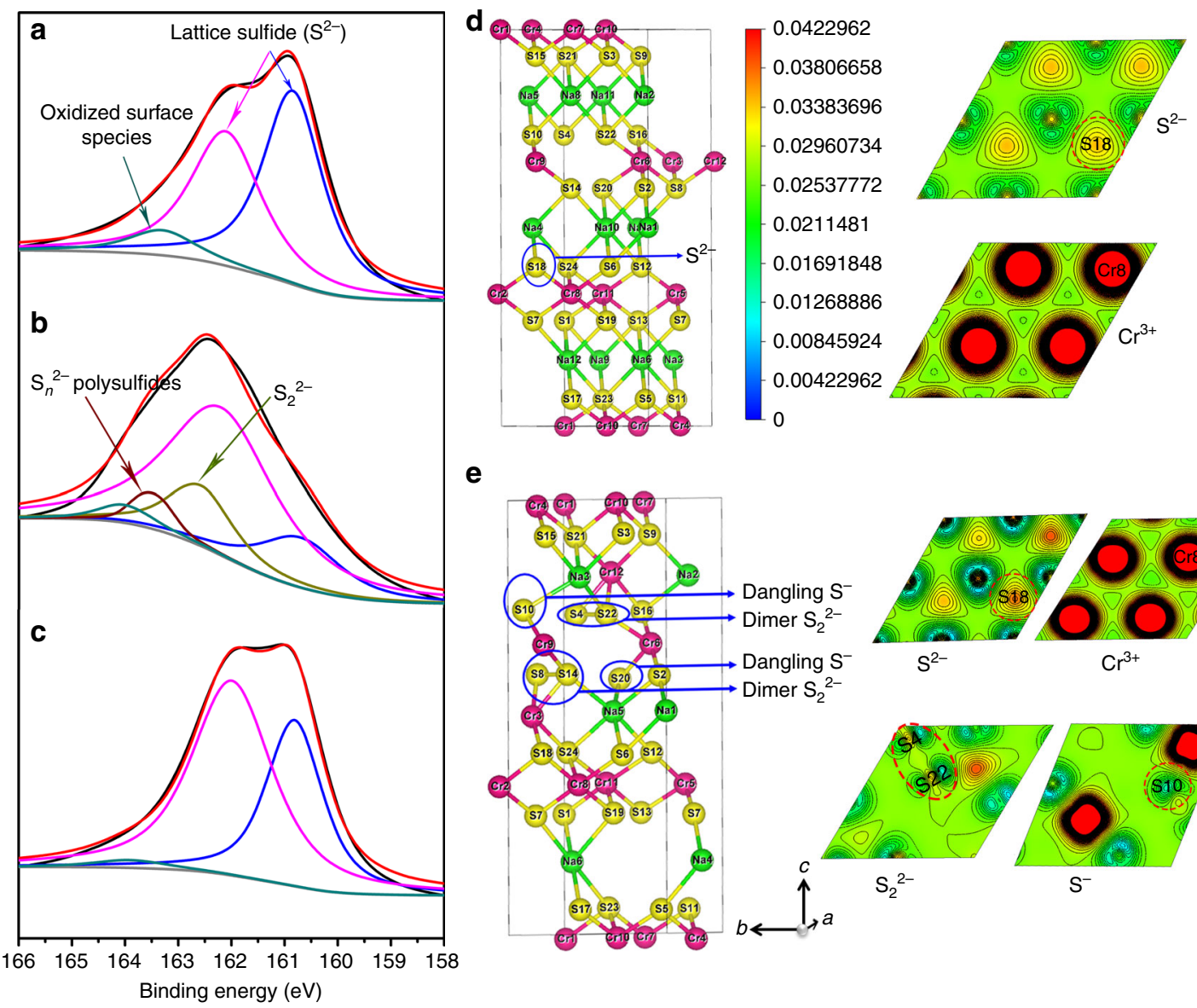

$\mathbf{e}$
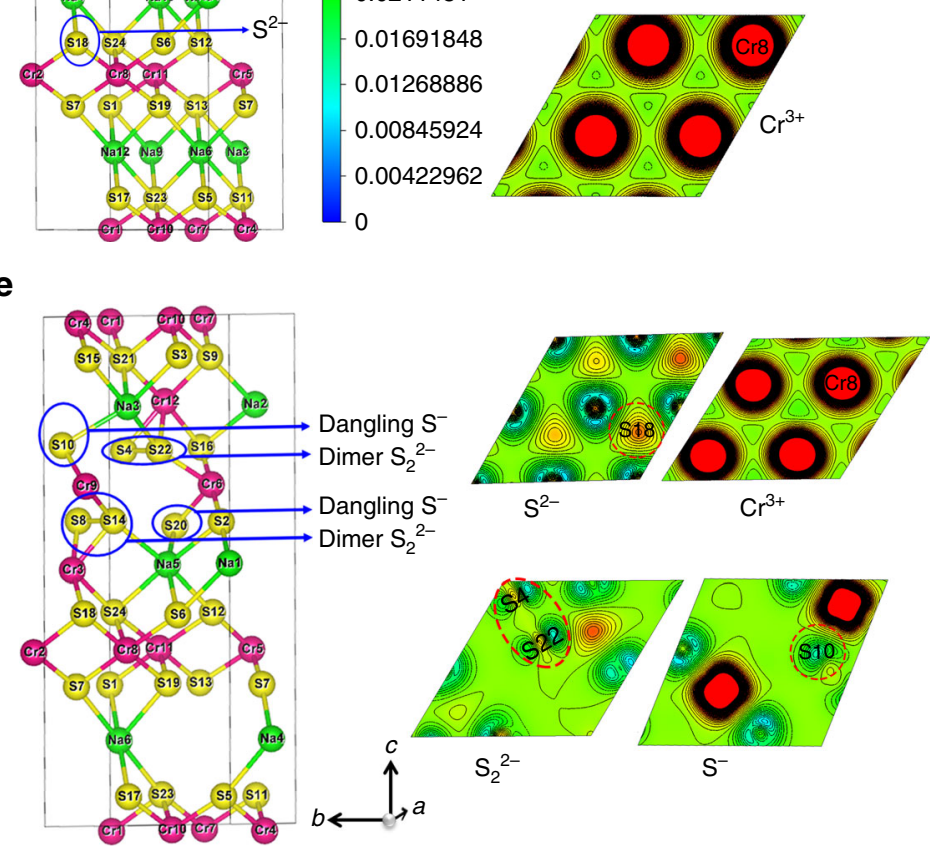

Fig. 5 Detection of $\mathrm{S}$ species evolution during various charge-discharge stages. S $2 p$ XPS spectra of $\mathrm{NaCrS}_{2}$ samples, a pristine, $\mathbf{b}$ after charging to $3.0 \mathrm{~V}$, and $\mathbf{c}$ after discharging to $1.5 \mathrm{~V}$. Crystal structures and electron density contours of $\mathbf{d}$ pristine $\mathrm{NaCrS}_{2}$ and $\mathbf{e ~} \mathrm{Na}_{0.5} \mathrm{CrS}_{2}$ with $1 / 6 \mathrm{Cr} / \mathrm{V}^{\prime} \mathrm{Na}$ antisite $\left(2 \times 2 \times 1\right.$ conventional cells). Selected planes are through the $\mathrm{Cr}$ and S ions labeled in crystal structures. The contour unit is e/Bohr ${ }^{3}(1 \mathrm{Bohr}=0.529 \AA)$

160.9 and $162.2 \mathrm{eV}$ are attributable to the lattice sulfide $\mathrm{S}^{2-}$, while the peak at $164.0 \mathrm{eV}$ can be explained from certain surface oxidization of species ${ }^{33,34}$. After full charge (Fig. 5b), the majority of $\mathrm{S}^{2-}$ is oxidized to higher valance states with higher binding energies as expected. The new peaks at 162.6 and $163.6 \mathrm{eV}$ are well assigned to $\mathrm{S}_{2}{ }^{2-}$ and short-chain polysulfides $\left(\mathrm{S}_{n}{ }^{2-}, 2<n<8\right)^{35-37}$, respectively. After discharge (Fig. $5 \mathrm{c}$ ), it is obvious that two peaks from $\mathrm{S}_{2}{ }^{2-}$ disappear along with the spectrum shape recovering to that of the initial, further confirming reversible redox of sulfur during charge and discharge processes.

DFT calculations. Figure $6 \mathrm{a}-\mathrm{c}$ shows the density of states of $\mathrm{Cr}-3 d$ and $\mathrm{S}-3 p$ in pristine $\mathrm{NaCrS}_{2}$. The band gap of $1.27 \mathrm{eV}$ for $\mathrm{NaCrS}_{2}$ is close to that of $1.16 \mathrm{eV}$ obtained with the atomic sphere approximation $^{38}$. Furthermore, the calculated magnetic moment of pristine $\mathrm{NaCrS}_{2}\left(3.322 \mu_{\mathrm{B}}\right)$ is slightly larger than the experimental value $\left(3 \mu_{\mathrm{B}}\right)^{38}$. Figure $6 \mathrm{~b}, \mathrm{c}$ also shows that the vast majority states ranging from -5 to $-0.49 \mathrm{eV}$ are occupied by $\mathrm{Cr}-3 d$ and these states are mainly contributed by $t_{2 g}$, which further confirms that the electron configuration of $\mathrm{Cr}^{3+}$ is the $t_{2 g}{ }^{3}(\uparrow) e_{g}^{0}(\uparrow)$. Most important is that the majority states from -0.49 to the Fermi level $\left(E_{\mathrm{F}}\right)$ and the minority states from $-5 \mathrm{eV}$ to $E_{\mathrm{F}}$ originate from S-3p band (See the inset in Fig. 6a). This is in excellent agreement with the angle-resolved photoemission experiment revealing $\mathrm{Cr}-3 d$ bands below the top of S-3p bands ${ }^{39}$.
The ground state configuration of $\mathrm{Na}_{1-x} \mathrm{CrS}_{2}$ with different $\mathrm{Na}$ concentrations ranging from $x=0$ to $x=0.5$ are determined by cluster expansion and the results are shown in Supplementary Figs. 9-13. Based on the ground state configuration of $\mathrm{Na}_{0.5} \mathrm{CrS}_{2}$ (without $\mathrm{Cr} / \mathrm{V}^{\prime}{ }_{\mathrm{Na}}$ antisite) obtained from the cluster expansion and by referring to the XRD and STEM results in Figs. 2 and 3, we build 103 possible configurations with $\mathrm{Cr} / \mathrm{V}^{\prime}{ }_{\mathrm{Na}}$ antisite $(1 / 6 \mathrm{Cr}$ in the $\mathrm{V}^{\prime}{ }_{\mathrm{Na}}$ ), whose lattice parameters and total energies are summarized in Fig. 6d-f and Supplementary Tables 3 and 4. As shown in Fig. 6, lattice parameters $a^{\prime}\left(a^{\prime}\right.$ : lattice parameter of $2 \times 2 \times 1$ conventional cell, $a^{\prime}$ is equal to $2 a$ ) of all configurations are smaller by $0.02376-0.2297 \AA$ than that of pristine $\mathrm{NaCrS}_{2}$. Interestingly, a configuration (red square) shows a lowest total energy and the $c$ axis length is close to that of pristine $\mathrm{NaCrS}_{2}$ (19.342 vs. $19.464 \AA$ ), but shorter by $1.205 \AA$ than that of $\mathrm{Na}_{0.5} \mathrm{CrS}_{2}$ without $\mathrm{Cr} / \mathrm{V}^{\prime}{ }_{\mathrm{Na}}$ antisite. Actually, as compared with a sharp increase of lattice parameter $c$ of $\mathrm{Na}_{1-x} \mathrm{CrS}_{2}$ without antisite (from $19.464 \AA$ at $x=0$ to $20.622 \AA$ at $x=1 / 2$ ) as shown in Supplementary Fig. 14, the almost constant lattice parameter $c$ of $\mathrm{Na}_{1-x} \mathrm{CrS}_{2}$ with $1 / 12 \mathrm{Cr} / \mathrm{V}^{\prime}{ }_{\mathrm{Na}}$ antisite is also obtained. Besides, the lattice parameter changes due to the desodiation for $\mathrm{NaCrS}_{2}$ $(\Delta a=-0.17 \%$ and $\Delta c=0.0 \%)$ are much smaller than those for typical layered $\mathrm{LiMO}_{2}$ family ${ }^{21}$.

We calculate the Na hopping barrier by $o$ - $t$ - $o$ pathway (moving from one octahedral site to an intermediate tetrahedral site, then to another octahedral site) in $\mathrm{Na}_{0.5} \mathrm{CrS}_{2}$ with $1 / 6 \mathrm{Cr} / \mathrm{V}^{\prime}{ }_{\mathrm{Na}}$ antisite. As shown in Supplementary Fig. 16, the calculated Na migration barrier of $0.33 \mathrm{eV}$ is comparable to the typical 1-TM barrier values $(\sim 0.3 \mathrm{eV})$ in layered oxides ${ }^{40}$, indicating the reduced 

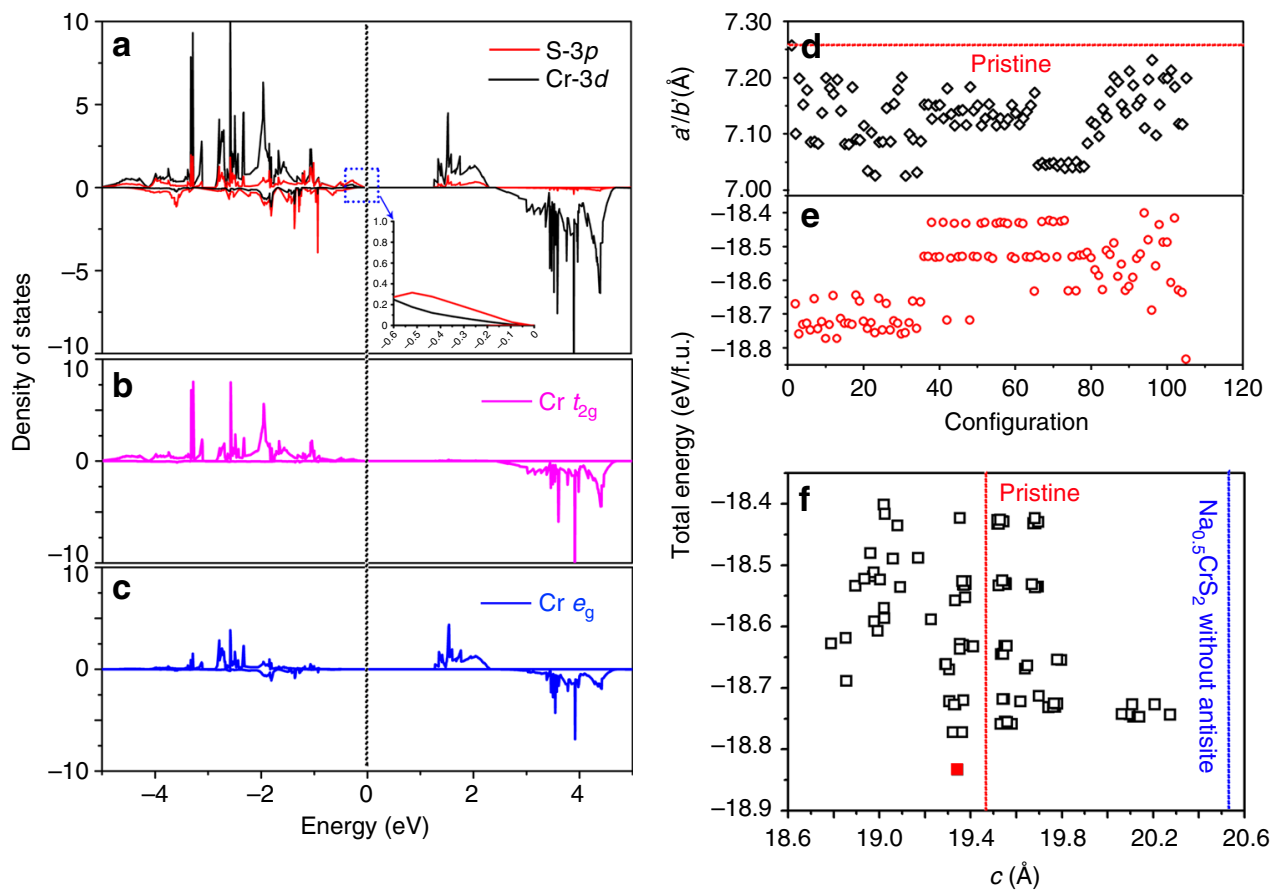

Fig. $6 \mathrm{DOS}$ and $\mathrm{Cr} / \mathrm{V}^{\prime}{ }_{\mathrm{Na}}$ antisite. a-c Density of states of $\mathrm{NaCrS}_{2}$. d, e Calculated lattice parameters $a^{\prime} / b^{\prime}$ and total energies of $2 \times 2 \times 1$ conventional cells and $\mathbf{f}$ dependence of calculated total energy of $\mathrm{Na}_{0.5} \mathrm{CrS}_{2}$ with $1 / 6 \mathrm{Cr} / \mathrm{V}^{\prime} \mathrm{Na}$ antisite on lattice parameter $c$. The total energy unit is eV/f.u.

tetrahedron height. This result suggests that the $\mathrm{Cr} / \mathrm{V}^{\prime}{ }_{\mathrm{Na}}$ antisite has the positive effect on $\mathrm{Na}$ diffusion. As shown in Supplementary Fig. 17a, along with extraction of $\mathrm{Na}^{+}$from $\mathrm{NaCrS}_{2}$, Cr first travels to the Na layer via the cross-layer migration, and then realizes the intra-layer migration, which acts as a "glue" between the Cr-S layers. It shortens the interlayer distance, so the length of $c$ axis decreases. Based on XRD, XAS, STEM, and first-principles calculation results, the "abnormal" unit cell breathing of $\mathrm{NaCrS}_{2}$ upon charge is influenced significantly by cross-layer migration of $\mathrm{Cr}$ accompanied by an energy barrier of $0.83 \mathrm{eV}$ (Supplementary Fig. 17b). It is noted that the energy barrier during the electrochemical charge/discharge process should be lower. Such a migration of $\mathrm{Cr}^{3+}$ ions can reduce the lattice expansion along the $c$ direction, and then serves as 'pillar' to prevent the structure collapse.

In order to further characterize the electronic structure during the desodiation process, we plot the charge densities of pristine $\mathrm{NaCrS}_{2}$ and $\mathrm{Na}_{0.5} \mathrm{CrS}_{2}$ and $1 / 6 \mathrm{Cr} / \mathrm{V}^{\prime}{ }_{\mathrm{Na}}$ antisite and summarize $\mathrm{Cr}-\mathrm{S}, \mathrm{Na}-\mathrm{S}$, and $\mathrm{S}-\mathrm{S}$ distances related to all $\mathrm{S}$ ions in $2 \times 2 \times 2$ $\mathrm{Na}_{0.5} \mathrm{CrS}_{2}$ with $1 / 6 \mathrm{Cr} / \mathrm{V}^{\prime}{ }_{\mathrm{Na}}$ antisite conventional cell, as shown in Fig. 5d-e and Supplementary Table 5. As compared with $\mathrm{NaCrS}_{2}$, the charge density distribution of $\mathrm{Cr}-3 d$ states in $\mathrm{Na}_{0.5} \mathrm{CrS}_{2}$ is nearly unchanged, indicating that $\mathrm{Cr}$ ions do not take part in redox reaction during charge/discharge process. Instead, it is found that there are two pairs of dimers $\mathrm{S}_{2}{ }^{2-}$ with an S-S distance of $2.083 \AA$, two dangling $\mathrm{S}^{-}$ions with two-coordinated $\mathrm{Cr}$ ions and others are general $S^{2-}$ ions. It should be emphasized that the usage of the larger-size supercell is expected to give polysulfides ions. The previous XPS and XANES data shown in Figs. 4 and 5 can be well explained by the calculation results.

\section{Discussion}

Previous studies on the electrochemistry of sulfur-based electrode materials mainly involve the conversion reaction between two or three species, such as between $\mathrm{LiCrS}_{2}$ and $\mathrm{Cr}+\mathrm{Li}_{2} \mathrm{~S}^{7}$, between $\mathrm{VS}_{4}$ and $\mathrm{Li}_{2} \mathrm{~S}+\mathrm{V}^{41}$, between $\mathrm{CuCr}_{2} \mathrm{~S}_{4}$ and $\mathrm{Cu}+\mathrm{Cr}_{2} \mathrm{~S}_{4}{ }^{15}, 42$, between
$\mathrm{Li}_{2} \mathrm{FeS}_{2}$ and $\mathrm{FeS}_{2}{ }^{43}$, and between sulfur and $\mathrm{Li}_{2} \mathrm{~S}^{44}$. The oxidation of $\mathrm{S}^{2-}$ was revealed in some of layered sulfides. For example, the deintercalation of copper from $\mathrm{Cu}\left[\mathrm{Cr}_{2}\right] \mathrm{S}_{4}$ with the placement of $\mathrm{Cr}^{4+} / \mathrm{Cr}^{3+}$ couples below the top of $\mathrm{S}-3 p$ state results in the itinerant holes in the S-3p bands. However, copper could not be reversibly intercalated into $\left[\mathrm{Cr}_{2}\right] \mathrm{S}_{4}{ }^{15}$. Furthermore, the holes in the S-3p bands are not trapped out at $\mathrm{S}_{2}{ }^{2-}$ as discussed by Goodenough $^{42}$. In layered sulfides of $\mathrm{LiV}_{1-y} \mathrm{M}_{y} \mathrm{~S}_{2}$ and $\mathrm{LiTi}_{1-y} \mathrm{M}_{y} \mathrm{~S}_{2}$ $(\mathrm{M}=\mathrm{Cr} / \mathrm{Fe})$, the $\mathrm{V}(\mathrm{IV}) / \mathrm{V}(\mathrm{III})$ and $\mathrm{Ti}(\mathrm{IV}) / \mathrm{Ti}(\mathrm{III})$ couples are situated at the top of S-3p states. The holes in S-3p states could also be achieved during lithium removal. However, there are sufficient cation- $3 d$ characters from $\mathrm{V}$ or Ti enough to prevent the formation of $p$ - $p$ antibonding states. Dahn et al. ${ }^{43}$ investigated the electrochemical mechanism of $\mathrm{Li} / \mathrm{FeS}_{2}$ and $\mathrm{Li} / \mathrm{Li}_{2} \mathrm{FeS}_{2}$, their results indicated that the deintercalation of $\mathrm{Li}$ from $\mathrm{Li}_{2} \mathrm{FeS}_{2}$ involved $\mathrm{Fe}^{3+} \mathrm{S}^{2-}\left(\mathrm{S}_{2}\right)^{2-}{ }_{1 / 2}$, in which there is a strong Fe $(3 d)-\mathrm{S}(3 p)$ overlap $^{45}, 46$. These works indicated the feasibility of inducing the anionic redox by forming the $\left(\mathrm{S}_{2}\right)^{n-}$ species reversibly ${ }^{47}$. On the other hand, previously reported $S$-based intercalation-type compounds $\mathrm{Li}_{1-x} \mathrm{CrS}_{2}$ only delivered a low capacity of $30 \mathrm{mAh} \mathrm{g}^{-142}$. In this work, the reversible discharge capacity of $95 \mathrm{mAh} \mathrm{g}^{-1}$ is presented. The very little change of lattice parameter $c$ and $100 \%$ coulombic efficiency during the cycles are quite impressive. By charging up to higher voltages, larger reversible capacities of $120 \mathrm{mAh} \mathrm{g}^{-1}$ can be achieved (Supplementary Fig. 18), and a progressive cationic redox reaction may be involved. Our experimental and DFT calculation results demonstrate that the redox of sulfur is mainly triggered by unique band structure of S-3p of $\mathrm{NaCrS}_{2}$ and isolated S-3p orbital introduced by $\mathrm{Cr} / \mathrm{V}^{\prime}{ }_{\mathrm{Na}}$ antisite, and holes in sulfur orbital with a high concentration condense into dianion $\mathrm{S}_{2}{ }^{2-}$.

In layered compounds, a redox couple energy position relative to the top of an anion $p$ band could determine the nature of deintercalation/intercalation reactions. The active $\mathrm{TM}^{n} / \mathrm{TM}^{n+1}$ redox couple as a single cationic redox reaction in the layered transition metal compounds, such as $\mathrm{LiCoO}_{2}$, locates at the top of $\mathrm{O}^{2-} p$ band (Supplementary Fig. 19a). The cumulative 
$\mathrm{Ru}(\mathrm{Ir})^{n} / \mathrm{Ru}(\mathrm{Ir})^{n+1}$ and $\mathrm{O}^{2-} / \mathrm{O}_{2}{ }^{2-}$ redox couples of layered $\mathrm{Li}_{2} \mathrm{MO}_{3}{ }^{9}, 10$ as cationic and anionic redox reactions exhibit a partial overlap at higher potential due to the strong covalent mixing, which can expand the half occupied couple to an itinerant band between $\mathrm{Ru}(\mathrm{Ir}) d$ and $\mathrm{O}^{2-} p$ bands (Supplementary Fig. 19b). As shown in Fig. 6a, the $\mathrm{Cr}^{4+} / \mathrm{Cr}^{3+}$ couple in layered $\mathrm{NaCrS}_{2}$ is pinned below the $\mathrm{S}^{2-} / \mathrm{S}_{2}{ }^{2-}$ redox couple, so the empty antibonding states of the redox couple are dominated by $S p$ band leading to a single anionic redox reaction. The $\mathrm{S}_{2}{ }^{2-} / \mathrm{S}^{2-}$ couple of $\mathrm{NaCrS}_{2}$ provides a charge potential of $2.8 \mathrm{~V}$ for $\mathrm{Na}^{+}$deintercalation from the octahedral sites if the top of $\mathrm{S}_{2}{ }^{2-} / \mathrm{S}^{2-}$ couple and the pinned $\mathrm{Cr} 3 d$ band are both stabilized by $\mathrm{Cr}$ migration into partially occupied $\mathrm{Na}$ layer. DFT calculation results indicate that the formation of $\mathrm{Cr} / \mathrm{V}^{\prime}{ }_{\mathrm{Na}}$ antisite involves three substeps (Supplementary Fig. 17): $\mathrm{Cr}$ first travels from $\mathrm{Cr}$ site to $\mathrm{Na}$ layer via cross-layer migration, and then travels from $\mathrm{Na}$ vacancy to another by the distance of $3.446 \AA$. Finally, via divacancy mechanism, Na migrates from the original lattice site to adjacent vacancy by the distance of $3.629 \AA$. It means, $\mathrm{Cr}$ migration from $\mathrm{Na}-\mathrm{S}-\mathrm{Cr}$ configuration to $\mathrm{Na}$ vacancy changes the configuration symmetry around S, resulting in the formation of Na-S- $\square$ ( $\square$ : Vacancy) configuration. Thus, there will be an isolated S $3 p$ orbital, indicating the non-bonding sulfur hole states, which have ionic character rather than covalent character. At a larger concentration, these sulfur holes condense into dianion $\mathrm{S}_{2}{ }^{2}$ - as shown in Fig. 5e. The reaction potential based on the single anionic redox chemistry of $\mathrm{S}^{2-} / \mathrm{S}_{2}{ }^{2-}$ is relatively low. Nevertheless, its unique features with "abnormal" unit cell breathing behavior (constant $c$ axis during charge and discharge) and redox chemistry $\mathrm{S}^{2-} / \mathrm{S}_{2}{ }^{2-}$ triggered by $\mathrm{Cr} / \mathrm{V}^{\prime}{ }_{\mathrm{Na}}$ antisite enrich the in-depth understanding for the nature of redox reaction of layered intercalation compounds. The single anionic redox chemistry of $\mathrm{S}^{2-} / \mathrm{S}_{2}{ }^{2-}$ may open a new research domain and provide new perspectives on how to design the composition and structure of high-capacity intercalation-type layered metal sulfides for rechargeable batteries by tuning the hybridization of other transition-metal $d$ and S $3 p$ bands or by designing double anion systems with $\mathrm{O}$ and $\mathrm{S}$ elements.

\section{Methods}

Sample preparation. To synthesize the $\mathrm{NaCrS}_{2}$ powder materials, a well-grounded mixture of $\mathrm{Na}_{2} \mathrm{~S}, \mathrm{~S}$, and $\mathrm{Cr}$ in stoichiometry was placed into carbon-coated quartz tubes. They were heated to $900^{\circ} \mathrm{C}$, kept at that temperature for $6 \mathrm{~h}$, and then cooled down slowly for over $3 \mathrm{~h}$ to $300^{\circ} \mathrm{C}$, followed by quenching. All preparation was performed under argon unless otherwise noted.

Electrochemical characterization. A slurry of $\mathrm{NaCrS}_{2}$ (70 wt\%), conductive carbon black (20 wt\%), and polyvinylidenefluoride (Sigma-Aldrich, $10 \mathrm{wt} \%$ ) dispersed in $\mathrm{N}$-methyl-2-pyrrolidone (Sigma-Aldrich) was coated on aluminum foil. Two thousand thirty-two coin cells were used for electrochemical test. The electrolyte consisted of $1 \mathrm{M} \mathrm{NaClO}_{4}$ dissolved in 1:1 (volume) ethylene carbonate/ dimethyl carbonate. Electrochemical performance measurements were carried out on a LAND battery tester.

In situ XRD measurements. XRD data were carried out at National Synchrotron Light Source (beamline $\times 14 \mathrm{~A}$ ) at Brookhaven National Laboratory. The wavelength of the X-ray was $0.7747 \AA$. A home-made electrochemical cell with X-ray windows was used. The angles of XRD spectra were switched to the angles for $\mathrm{Cu}-\mathrm{Ka}(\lambda=1.54 \AA)$, in order to compare with the literature easily.

XAS measurements. Ex situ Cr K-edge XAS spectra were measured at Advanced Photon Source (beamline 12BM) at Argonne National Laboratory. Ex situ S K-edge XAS spectra were obtained at beamline 4B7A in Beijing Synchrotron Radiation Facility. The bending magnet beamline covers the spectral range from 2050 to $5700 \mathrm{eV}$, with energy resolving power up to 7000 and a beam size of $3 \mathrm{~mm} \times 1 \mathrm{~mm}$. The EXAFS and XANES spectra were processed using Artemis and Athena software packages ${ }^{48}$.
STEM measurements. The detailed measurement set-up was described elsewhere $^{49}$

XPS characterization. XPS was carried out on a PHI 5000C ESCA System with monochromatic Al-Ka X-ray source. The $\mathrm{C} 1$ s peak at $285.0 \mathrm{eV}$ from hydrocarbon contamination was used to calibrate the binding energy.

EPR characterization. EPR spectra were collected on a Bruker EMX-8/ 2.7 spectrometer. Microwave power was set to $2 \mathrm{mV}$.

DFT calculations. Based on the projector-augmented wave method within DFT theory ${ }^{50}$, conducted with the VASP program ${ }^{51}$, ferromagnetic spin-polarized calculations were carried out. We used the Perdew-Burke-Ernzerhof functional for exchange correlation ${ }^{52}$. We set an effective $U_{\text {eff }}$ value to $3.5 \mathrm{eV}$ as discussed in electronic structure calculations on $\mathrm{MCrS}_{2}(\mathrm{M}=\mathrm{Li}, \mathrm{Na}, \mathrm{K} \text {, and } \mathrm{Ag})^{53}$. The plane wave cutoff energy and Monkhorst-Pack $k$-point mesh were set to $550 \mathrm{eV}$ and $2 \times 2 \times 1$ for $\mathrm{NaCrS}_{2}$ conventional cell, respectively. As for the calculation of the electronic density of states, $4 \times 4 \times 1 k$-point mesh for the conventional cell and the modified tetrahedron method were used. The above parameters made the total energy converged to $2 \mathrm{meV}$ per atom. The calculated structural parameters of $\mathrm{NaCrS}_{2}$ are consistent with experimental ones ( $a$ and $c: 3.627582$ and $19.446446 \AA$ vs. 3.5270 and $19.3506 \AA$ ). To determine the energy barriers for $\mathrm{Na}$ or $\mathrm{Cr}$ ion diffusion in $\mathrm{NaCrS}_{2}$, the climbing-image nudged elastic band method ${ }^{54}$ was employed for searching the minimum-energy path.

Data availability. The main data supporting the findings of this study are available within the article and its Supplementary Information files. Extra data are available from the corresponding author upon request.

Received: 24 March 2017 Accepted: 18 July 2017

Published online: 18 September 2017

\section{References}

1. Whittingham, M. S. Lithium batteries and cathode materials. Chem. Rev. 104 4271-4301 (2004).

2. Whittingham, M. S. Ultimate limits to intercalation reactions for lithium batteries. Chem. Rev. 114, 11414-11443 (2014).

3. Yabuuchi, N., Kubota, K., Dahbi, M. \& Komaba, S. Research development on sodium-ion batteries. Chem. Rev. 114, 11636-11682 (2014).

4. Ozawa, K. Lithium-ion rechargeable batteries with $\mathrm{LiCoO}_{2}$ and carbon electrodes: the $\mathrm{LiCoO}_{2} / \mathrm{C}$ system. Solid State Ionics 69, 212-221 (1994).

5. Kubota, K. et al. New insight into structural evolution in layered $\mathrm{NaCrO}_{2}$ during electrochemical sodium extraction. J. Phys. Chem. C 119, 166-175 (2015).

6. Yabuuchi, N. \& Ohzuku, T. Novel lithium insertion material of $\mathrm{LiCo}_{1 / 3}$ $\mathrm{Ni}_{1 / 3} \mathrm{Mn}_{1 / 3} \mathrm{O}_{2}$ for advanced lithium-ion batteries. J. Power Sources 119-121, 171-174 (2003).

7. Kim, Y., Park, K.-S., Song, S.-H., Han, J. T. \& Goodenough, J. B. Access to $\mathrm{M}^{3+} / \mathrm{M}^{2+}$ redox couples in layered $\mathrm{LiMS}_{2}$ sulfides $(\mathrm{M}=\mathrm{Ti}, \mathrm{V}, \mathrm{Cr})$ as anodes for Li-Ion battery. J. Electrochem. Soc. 156, A703-A708 (2009).

8. Luo, K. et al. Charge-compensation in $3 \mathrm{~d}$-transition-metal-oxide intercalation cathodes through the generation of localized electron holes on oxygen. Nat. Chem 8, 684-691 (2016).

9. Sathiya, M. et al. Reversible anionic redox chemistry in high-capacity layeredoxide electrodes. Nat. Mater. 12, 827-835 (2013).

10. Sathiya, M. et al. Origin of voltage decay in high-capacity layered oxide electrodes. Nat. Mater. 14, 230-238 (2015).

11. McCalla, E. et al. Understanding the roles of anionic redox and oxygen release during electrochemical cycling of lithium-rich layered $\mathrm{Li}_{4} \mathrm{FeSbO}_{6}$. J. Am. Chem. Soc. 137, 4804-4814 (2015).

12. McCalla, E. et al. Visualization of O-O peroxo-like dimers in high-capacity layered oxides for Li-ion batteries. Science 350, 1516-1521 (2015).

13. Seo, D. H. et al. The structural and chemical origin of the oxygen redox activity in layered and cation-disordered Li-excess cathode materials. Nat. Chem 8 , 692-697 (2016).

14. Delmas, C. Battery materials: operating through oxygen. Nat. Chem 8, 641-643 (2016).

15. Rouxel, J. Anion-cation redox competition and the formation of new compounds in highly covalent systems. Chem. Eur. J. 2, 1053-1059 (1996).

16. $\mathrm{Du}, \mathrm{K}$. et al. Exploring reversible oxidation of oxygen in a manganese oxide. Energy Environ. Sci. 9, 2575-2577 (2016) 
17. Wulff, H., Mohan Rao, M. \& Scholz, F. Crystallographic evidence for the formation of a continuous series of mixed crystals between $\mathrm{NiO}$ and $\mathrm{LiNiO}_{2}$ Chem. Mater. 15, 988-993 (2003).

18. Tran, N., Croguennec, L., Jordy, C., Biensan, Ph. \& Delmas, C. Influence of the synthesis route on the electrochemical properties of $\mathrm{LiNi}_{0.425} \mathrm{Mn}_{0.425} \mathrm{Co}_{0.15} \mathrm{O}_{2}$. Solid State Ionics 176, 1539-1547 (2005).

19. $\mathrm{Lu}, \mathrm{X}$. et al. New insight into the atomic structure of electrochemically delithiated $\mathrm{O} 3-\mathrm{Li}_{(1-x)} \mathrm{CoO}_{2}(0 \leq x \leq 0.5)$ nanoparticles. Nano Lett. 12, 6192-6197 (2012).

20. Lee, E., Sahgong, S. H., Johnson, C. S. \& Kim, Y. Comparative electrochemical sodium insertion/extraction behavior in layered $\mathrm{Na}_{x} \mathrm{VS}_{2}$ and $\mathrm{Na}_{x} \mathrm{TiS}_{2}$. Electrochim. Acta 143, 272-277 (2014).

21. Zhou, Y.-N. et al. Tuning charge-discharge induced unit cell breathing in layer-structured cathode materials for lithium-ion batteries. Nat. Commun. 5, 5381 (2015).

22. Kumada, N., Muramatu, S., Muto, F. \& Kinomura, N. Topochemical reactions of $\mathrm{Li}_{x} \mathrm{NbO}_{2}$. J. Solid State Chem. 73, 33-39 (1988).

23. Lyu, Y. C. et al. Atomic insight into electrochemical inactivity of lithium chromate $\left(\mathrm{LiCrO}_{2}\right)$ : Irreversible migration of chromium into lithium layers in surface regions. J. Power Sources 273, 1218-1225 (2015).

24. Depicciotto, L. A., Thackeray, M. M., David, W. I. F., Bruce, P. G. \& Goodenough, J. B. Structural characterization of delithiated $\mathrm{LiVO}_{2}$. Mater. Res. Bull. 19, 1497-1506 (1984).

25. Zhou, Y. N. et al. Phase transition behavior of $\mathrm{NaCrO}_{2}$ during sodium extraction studied by synchrotron-based X-ray diffraction and absorption spectroscopy. J. Mater. Chem. A 1, 11130-11134 (2013).

26. Wang, Q. et al. Direct observation of sulfur radicals as reaction media in lithium sulfur batteries. J. Electrochem. Soc. 162, A474-A478 (2015).

27. Mukai, K. et al. Thermally activated spin fluctuations in stoichiometric $\mathrm{LiCoO}_{2}$ clarified by electron paramagnetic resonance and muon-spin rotation and relaxation measurements. Phys. Rev. B 89, 094406 (2014).

28. Vicente, F. S. D. et al. EPR, optical absorption and luminescence studies of $\mathrm{Cr}^{3+}$-doped antimony phosphate glasses. Opt. Mater. 38, 119-125 (2014).

29. Singh, V., Chakradhar, R. P. S., Rao, J. L. \& Zhu, J.-J. Studies on red-emitting $\mathrm{Cr}^{3+}$ doped barium aluminate phosphor obtained by combustion process. Mater. Chem. Phys. 111, 143-148 (2008).

30. Fischer, D. W. X-ray band spectra and electronic structure of TiS 2 . Phys. Rev. B 8, 3576-3582 (1973).

31. Wu, Z. Y. et al. Sulfur $K$-edge X-ray-absorption study of the charge transfer upon lithium intercalation into titanium disulfide. Phys. Rev. Lett. 77, 2101-2104 (1996).

32. Moreau, P., Ouvrard, G., Gressier, P., Ganal, P. \& Rouxel, J. Electronic structures and charge transfer in lithium and mercury intercalated titanium disulfides. J. Phys. Chem. Solids 57, 1117-1122 (1996).

33. Smart, R. S. C., Skinner, W. M. \& Gerson, A. R. XPS of sulphide mineral surfaces: metal-deficient, polysulphides, defects and elemental sulphur. Surf. Interface Anal. 28, 101-105 (1999).

34. Xiong, S. L. \& Zeng, H. C. Serial ionic exchange for the synthesis of multishelled copper sulfide hollow spheres. Angew. Chem. 51, 949-952 (2012).

35. Zhu, L. et al. Investigation of $\mathrm{CoS}_{2}$-based thin films as model catalysts for the oxygen reduction reaction. J. Catal. 258, 235-242 (2008).

36. Bonnissel-Gissinger, P., Alnot, M., Ehrhardt, J. J. \& Behra, P. Surface oxidation of pyrite as a function of pH. Environ. Sci. Technol. 32, 2839-2845 (1998).

37. Mycroft, J. R., Bancroft, G. M., Mclntyre, N. S., Lorimer, J. W. \& Hill, I. R. Detection of sulphur and polysulphides on electrochemically oxidized pyrite surfaces by X-ray photoelectron spectroscopy and Raman spectroscopy. J. Electroanal. Chem. 292, 139-152 (1990).

38. Sebilleau, D., Guo, G. Y. \& Temmerman, W. M. A band model for the electronic and magnetic structure of $\mathrm{NaCrS}_{2}$. J. Phys. Condens. Matter. 1, 5653-5666 (1989).

39. Hughes, H. P., Parke, A. W., Williams, R. H. \& Barry, J. J. Photoemission and magnetic effects in $\mathrm{NaCrS}_{2}$. J. Phys. C 14, L1103-L1109 (1981).

40. Kang, K. \& Ceder, G. Factors that affect Li mobility in layered lithium transition metal oxides. Phys. Rev. B 74, 094105 (2006).

41. Britto, S. et al. Multiple redox modes in the reversible lithiation of highcapacity, peierls-distorted vanadium sulfide. J. Am. Chem. Soc. 137, 8499-8508 (2015).

42. Goodenough, J. B. \& Kim, Y. Locating redox couples in the layered sulfides with application to $\mathrm{Cu}\left[\mathrm{Cr}_{2}\right] \mathrm{S}_{4}$. J. Solid State Chem. 182, 2904-2911 (2009).

43. Fong, R. \& Dahn, J. R. Electrochemistry of pyrite-based cathodes for ambient temperature lithium batteries. J. Electrochem. Soc. 136, 3206-3210 (1989).

44. Barghamadi, M., Kapoor, A. \& Wen, C. A review on Li-S batteries as a high efficiency rechargeable lithium battery. J. Electrochem. Soc. 160, 1256-A1263 (2013).

45. Blandeau, L., Ouvrard, G., Calage, Y., Brec, R. \& Rouxel, J. Transition-metal dichalcogenides from disintercalation processes. Crystal structure determination and Mossbauer study of $\mathrm{Li}_{2} \mathrm{FeS}_{2}$, and its disintercalates $\mathrm{Li}_{\mathrm{x}} \mathrm{FeS}_{2}$, $(0.2 \leq \mathrm{x} \leq 2)$. J. Phys. 20, 4271-4281 (1987).

46. Goodenough, J. B. \& Fatseas, G. A. Mössbauer ${ }^{57} \mathrm{Fe}$ isomer shift as a measure of valence in mixed-valence iron sulfides. J. Solid State Chem. 41, 1-22 (1982).

47. Grimaud, A., Hong, W. T., Shao-Horn, Y. \& Tarascon, J. M. Anionic redox processes for electrochemical devices. Nat. Mater. 15, 121-126 (2016).

48. Ravel, B. \& Newville, M. Athena, artemis, hephaestus: data analysis for X-ray absorption spectroscopy using IFEFFIT. J. Synchrotron. Radiat. 12, 537-541 (2005).

49. Yue, J. L. et al. Discrete Li-occupation versus pseudo-continuous $\mathrm{Na}$-occupation and their relationship with structural change behaviors in $\mathrm{Fe}_{2}\left(\mathrm{MoO}_{4}\right)_{3}$. Sci. Rep 5, 8810 (2015).

50. Blochl, P. E. Projector augmented-wave method. Phys. Rev. B 50, 17953-17979 (1994).

51. Kresse, G. \& Furthmuller, J. Efficiency of ab-initio total energy calculations for metals and semiconductors using a plane-wave basis set. Comput. Mater. Sci. 6 , 15-50 (1996).

52. Perdew, J. P., Burke, K. \& Ernzerhof, M. Generalized gradient approximation made simple. Phys. Rev. Lett. 77, 3865-3869 (1996).

53. Ushakov, A., Kukusta, D., Yaresko, A. \& Khomskii, D. Magnetism of layered chromium sulfides $M \mathrm{CrS}_{2}(M=\mathrm{Li}, \mathrm{Na}, \mathrm{K}, \mathrm{Ag}$, and $\mathrm{Au})$ : a first-principles study. Phys. Rev. B 87, 014418 (2013).

54. Henkelman, G., Uberuaga, B. P. \& Jonsson, H. A climbing image nudged elastic band method for finding saddle points and minimum energy paths. J. Chem. Phys. 113, 9901-9904 (2000).

\section{Acknowledgements}

This work was supported by National Natural Science Foundation of China (U1430104, 51622207, 51502039, U1630134, and 51372228), National Key Research and Development Program of China (2016YFB0901504 and 2017YFB0701600), and Science \& Technology Commission of Shanghai Municipality (11JC 1400500), and Shanghai Pujiang Program (14PJ1403900). The work at Brookhaven National Laboratory was supported by the Assistant Secretary for Energy Efficiency and Renewable Energy, Office of Vehicle Technologies of the U.S. Department of Energy through the Advanced Battery Materials Research (BMR) Program under Contract No. DE-SC0012704. The authors gratefully acknowledge the help by beamline scientists at 12BM of Advanced Photon Source at Argonne National Laboratory, supported by the U.S. Department of Energy under Contract No. DE-AC02-06CH11357. The authors also thank BL14W1 of Shanghai Synchrotron Radiation Facility, the high performance computing platform of Shanghai University, and national supercomputer center in Guangzhou.

\section{Author contributions}

Z.-W.F. and S.-Q.S. supervised the research. Z.S., S.-Q.S., and Z.-W.F. wrote the manuscript. Z.S. and J.-L.Y. tested the electrochemical performance. Y.-N.Z. and X.-Q.Y. performed the XRD and XAS measurements. Z.S., J.-L.Y., L.-L.C., Q.W., and S.-Q.S conducted the DFT calculations. N.Z. and X.L. performed the S K-edge XANES experiments and processed the data. L.G. conducted STEM imaging.

\section{Additional information}

Supplementary Information accompanies this paper at doi:10.1038/s41467-017-00677-3.

Competing interests: The authors declare no competing financial interests.

Reprints and permission information is available online at http://npg.nature.com/ reprintsandpermissions/

Publisher's note: Springer Nature remains neutral with regard to jurisdictional claims in published maps and institutional affiliations.

Open Access This article is licensed under a Creative Commons Attribution 4.0 International License, which permits use, sharing, adaptation, distribution and reproduction in any medium or format, as long as you give appropriate credit to the original author(s) and the source, provide a link to the Creative Commons license, and indicate if changes were made. The images or other third party material in this article are included in the article's Creative Commons license, unless indicated otherwise in a credit line to the material. If material is not included in the article's Creative Commons license and your intended use is not permitted by statutory regulation or exceeds the permitted use, you will need to obtain permission directly from the copyright holder. To view a copy of this license, visit http://creativecommons.org/ licenses/by/4.0/

(C) The Author(s) 2017 